\title{
Research on Low-carbon Optimization Model of City Traffic
}

\author{
Mingyang Cuil, a, Qi Zhang',b \\ Department of Traffic and Transportation, Beijing Jiaotong University \\ No.3 Shang Yuan Cun, Hai Dian District, Beijing, China.100044 \\ a15125732@bjtu.edu.cn, bqizhang@bjtu.edu.cn
}

\begin{abstract}
Keywords: Low carbon; Traffic; Optimization model; Zhengzhou
Abstract: Climate change has been one of the most serious problems faced by people. In order to reduce $\mathrm{CO}_{2}$ emission, the study is to analyze reasonable traffic mode shares through the proposed optimization model. On the basis of literature review and experience on low carbon planning in traffic system, an optimization model is constructed with the objective of maximizing the ratio of traffic efficiency to carbon emissions by using fractional programing. The constraints include the aspects of traffic demand, development scales requirements, pollutant emissions, energy and land use. This paper analyses the case of Zhengzhou and combines the future plan, which can provide solid supports for the relevant decisions made by traffic sectors.
\end{abstract}

\section{Introduction}

With the development of China's economic, we have a lot of greenhouse gas emissions which account for a large share of the global emissions. According to the report of IEA, China's total carbon dioxide emissions have exceeded the EU's on 2004, and surpassed all of the other countries on 2007. China also proposed the target that by 2020 greenhouse gas emissions should be reduced by $40 \%$ to $45 \%$ compared with those in 2005.

Urban low-carbon traffic, which has the characteristics of energy-efficiency, low energy consumption, low pollution and low emissions, is a dynamic process of pursuing the equilirium point of social and economic development, traffic sustainable development and traffic low-carbon. In the process of urbanization, increasing in population, the number of motor vehicles, passenger and freight traffic, residents, and the transportation conflict between demand and supply, will all lead a substantial increase in traffic carbon emissions. Reducing urban carbon emissions is of great significance for easing the traffic situation and improving people's living standards.

The task of reviewing relevant literature is well served by the recent contributions. Robin Hickman[1] evaluated UK as the pioneer in low-carbon urban planning and practice in Transport and climate change: Simulating the options for carbon reduction in London. Sudhir Gota[2] proposed key solutions of low-carbon transport development: ASIF and ASI. Yifan Wang[3] adopted the method of centralized MOBILE emission factor model to determine the estimated vehicle emission factors research vehicle carbon emissions calculation in the case of Chengdu. Haikun Wang and Rongrong Zhang[4] divided vehicles into different types when calculating the carbon emissions of transportation unit. Peipei Jia and Cheng $\mathrm{Xu}[5]$ adopted the unit(L/100 person $\bullet \mathrm{km})$ to calculate estimated consumption when studying integrated traffic energy consumption in Xi'an. Qing Zhang and Xiaoma Tao[6] used the method of partial equilibrium comparative static analysis in the study of resident trip mode and low-carbon transportation. Ling Cheng[7] conducted a study of urban passenger traffic structure optimization based on low-carbon target by using multi-objective linear programming optimization. Haozhi Zhang and Ziyou Gao[8] utilized double-planning study of traffic network to design optimization algorithm.

Previous works only considered the carbon emissions and ignored the demand of traffic volume. This article will consider these two aspects and then build the fractional model. 


\section{Low-carbon optimization traffic model}

With the development of the society, urban consumption of resources, environmental quality and traffic efficiency, etc. all have a direct relationship with the model. In the paper the model takes only buses, rail, taxis and private cars into consideration. We take 2014 as the starting year, and optimize traffic travel structure for three planning periods of 2015-2016, 2017--2018 and 2019-2020.

Model assumptions:

(1) The city is a relatively closed system;

(2) The model ignores the city pollution and resource consumption due to inter-city traffic;

(3) The status of inter-city traffic demand is determined;

(4) The mode of traffic constitution is determined.

Urban traffic system with high efficiency, is bound to achieve the maximum of traffic flow, the minimum of traffic emissions and the maximum of the ratio of both, so the system can achieve the requirements of urban traffic to maximize efficiency, with the least carbon emissions and the most amount of traffic flow.

The fractional model is as follow:

$\operatorname{MAX} Z_{n}=\frac{\sum_{1}^{4} C_{i} \times x_{i}}{\sum_{1}^{4} \alpha_{i} \times x_{i}}$

The meaning of $i$ is shown in Table 1 .

Table 1 The meaning of $\mathrm{i}$

\begin{tabular}{c|cccc}
\hline $\mathrm{i}$ & 1 & 2 & 3 & 4 \\
\hline Transportation mode & bus & rail & taxi & private car \\
\hline
\end{tabular}

$Z_{n}$ represents traffic efficiency of urban traffic system in n-th year;

$C_{i}$ represents the weight of traffic volume of the mode $\mathrm{i}$ in urban traffic system. $\mathrm{C}$ is a multi-objective comprehensive evaluation, which means the contribution of different traffic mode on urban traffic efficiency improved;

$x_{i}$ represents incurred volume of the mode i in urban traffic system, person $\bullet \mathrm{km}$;

$\alpha_{i}$ represents carbon emission factor of the mode $\mathrm{i}$ in urban traffic system.

\section{Restrictions}

\section{(1) Restriction on traffic demand}

In urban traffic demand, the volume of all modes of traffic should not be less than the actual demand (or according to the relevant data prediction) in a year, thus:

$$
\sum_{1}^{4} x_{i} \leq \mathrm{D}_{n}
$$

$\mathrm{D}_{n}$ The actual volume demand of the passenger turnover, person $\bullet \mathrm{km}$.

And $\mathrm{D}_{n}$ can be calculated by traffic forecast model of four-step method. The formula can be expressed by:

$\mathrm{D}=\mathrm{T} \times \mathrm{ND} \times \frac{R}{N R}=\mathrm{T} \times \mathrm{ND} \times \sqrt{\frac{A}{N A}}$

T_- The total urban travel volume of planning year;

ND_-Average travel distance of residents;

$\mathrm{R}$ - The equivalent radius of the city in the planning year;

$\mathrm{NR}$ — The equivalent radius of the city in current year;

$\mathrm{A}$ - The area of the city in the planning year;

NA_- The area of the city in current year. 


\section{(2) Restriction on scale constraints}

Development of various modes of traffic should be based on the urban traffic planning, so the volume of various modes of traffic should be within the scale of planning, thus:

$0<T_{i}^{\min } \leq T_{i} \leq T_{i}^{\max }$

$T_{i}^{\min }$ _ The lower limit of turnover volume of mode $\mathrm{i}$;

$T_{i}^{\max }$ - The upper limit of turnover volume of mode $i$.

\section{(3) Restriction on emissions}

Constraint of carbon emissions is the core to build a low-carbon model of traffic. It is important to ensure that the total carbon dioxide emission is less than city allowable carbon dioxide emission.

$$
\sum_{1}^{4} \alpha_{i} \times x_{i} * y_{i} \leq E_{\mathrm{n} \text { carbon }}
$$

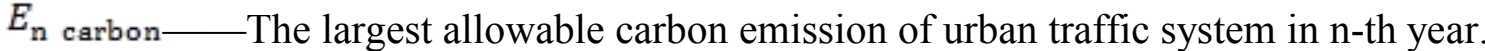

Under the condition that pollutant concentration has been identified, we can retrodict the source strength of the urban emission by box model. Then we calculate the pollutant emissions of the city in a certain period, and this is environmental capacity of the city. Environmental capacity model can be expressed by:

$\mathrm{Q}(\mathrm{T})=\mathrm{qST}$

$\mathrm{T}$;

$\mathrm{Q}(\mathrm{T})$ _ - The total amount of pollutants under the permission of atmospheric environment within

$\mathrm{q}-$ source strength, $\mathrm{mg} / \mathrm{m}^{2} \times s$;

$\mathrm{S}-$ Urban area $\left(\mathrm{m}^{2}\right)$;

$\mathrm{T}-$ Cycle.

q can be expressed by:

$\mathrm{q}=\frac{C_{s} u H}{\sqrt{S}}$

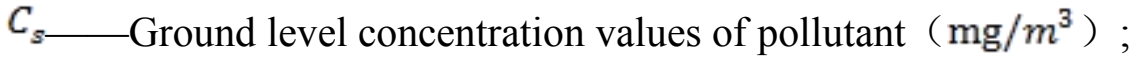

$\mathrm{u}-$ Dominant wind speed $(\mathrm{m} / \mathrm{s})$;

$\mathrm{H}$-Atmospheric mixing layer height $(\mathrm{m})$.

We define $\eta$ as a factor, which represents emission ratio of traffic sector and total air pollutants.

$Q_{\mathrm{T}}=\eta Q_{\mathrm{A}}$

Above all, urban traffic capacity can be expressed by:

$Q_{\mathrm{T}}=\eta C_{s} \mu H \sqrt{S}$

\section{(4)Restriction on energy consumption}

The total energy consumption does not exceed the defined maximum consumption.

$$
\sum_{1}^{4} e_{i} \times x_{i} \leq S_{\text {nenergy }}
$$

$e_{\tilde{i}}$ _-Energy consumption factor of the mode i of traffic in n-th year;

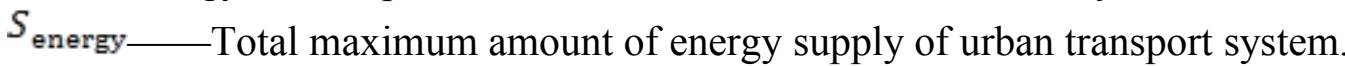

\section{(5) Restriction on land resources}

Because of the limits of urban land resources, the dynamic average area should be within per capita area.

$$
\frac{\sum_{1}^{4} l_{i} \times x_{i}}{\sum_{1}^{4} x_{i}} \leq \mathrm{LR}_{n}
$$

$l_{i}$ __ Dynamic per capita area of the mode i of traffic in n-th year, $\mathrm{m}^{2} /$ person;

$\mathrm{LR}_{n}$ _- Per capita area of traffic in the n-th year, $\mathrm{m}^{2} /$ person.

\section{(6) Non-negative constraint}

All parameters are non-negative. 


\section{Case Study}

Considering the population, growth of the road, strengthening of the public traffic system, rail transit construction, restrictions on private cars, investment on new energy bus, etc., we take the case of Zhengzhou and calculate the model by Lingo.

The traffic data of Zhengzhou is shown in Table 2.

Table 2 The basic traffic data of Zhengzhou

Average travel times 2.67

Average travel distance $\quad 8 \mathrm{~km}$

The average annual natural population growth $\quad 7 \%$

The average annual growth rate of road $\quad 2 \%$

Acceptable and tolerable distance of bus $\quad 6.8-9.7 \mathrm{~km}$

Acceptable and tolerable distance of rail 5.83-10km

Road area per capita

$6.19 m^{2}$

Energy consumption

$4.14 \mathrm{MJ} /$ person $\bullet \mathrm{d}$

The emission factor is shown in Table 3.

Table 3 Emission factor $(\mathrm{g} /$ person $\bullet \mathrm{km})$

\begin{tabular}{c|cccc}
\hline Category & bus & rail & taxi & private car \\
\hline $\mathrm{CO}$ & 40.38 & 10.09 & 2 & 2 \\
$\mathrm{NO}_{x}$ & 6.6 & 1.65 & 0.14 & 0.14 \\
\hline
\end{tabular}

According to the natural environment features of Zhengzhou, we calculate the emission limit as shown in Table 4.

Table 4 Emission limits

\begin{tabular}{c|cc}
\hline Emission & $\mathrm{CO}$ & $\mathrm{NO}_{x}$ \\
\hline Total limit of urban traffic $(\mathrm{kg} / \mathrm{d})$ & 635742 & 7755.8 \\
Total limit of urban passenger traffic $(\mathrm{kg} / \mathrm{d})$ & 381445 & 4653 \\
\hline
\end{tabular}

The consumption factor is shown in Table 5.

Table 5 Consumption factor $(\mathrm{MJ} /$ person $\bullet \mathrm{Km})$

\begin{tabular}{l|lccc}
\hline traffic & bus & rail & taxi & private car \\
\hline consumption & 0.714 & 0.322 & 5.59 & 2.795 \\
\hline
\end{tabular}

We also consider that new energy buses (natural gas) are popularized in Zhengzhou, and the proportion is increasing year after year. We assume the number of new energy bus increases by 1000 per year, which can reduce $90 \%$ of $\mathrm{CO}$ emissions, $40 \%$ of $\mathrm{NO}_{x}$ emissions, and $20 \%$ of $\mathrm{CO}_{2}$ emissions. And according to the current plan, several subway lines will be constructed and operated in the next few years. We estimate the volume of future rail transit via current data. The number of taxis is enough for Zhengzhou so the taxi occupancy will be steady. The development of private cars will be regulated and the occupancy will be slowly improved.

The result of the calculation is shown in Table 6. 
Table 6 The result

\begin{tabular}{c|ccccccc}
\hline year & $x_{1}$ & $x_{2}$ & $x_{3}$ & $x_{4}$ & Traffic efficiency & carbon emission(t) & $Z_{n}\left(\times 10^{-4}\right)$ \\
\hline 2014 & 9116.4 & 200 & 176.2 & 6167.7 & 557.67 & 1012955.51 & 5.70 \\
2016 & 10977.9 & 550 & 176.2 & 6254.4 & 670.83 & 1052354.30 & 6.37 \\
2018 & 12889.8 & 1000 & 176.2 & 6242.2 & 795.12 & 1094370.79 & 7.27 \\
2020 & 14853.3 & 1500 & 176.2 & 6431.1 & 926.11 & 1137772.54 & 8.14 \\
\hline
\end{tabular}

From the Table 6 we can conclude the traffic plan of Zhengzhou is effective. The volume of buses and rails has a significant growth, while the volume of taxis and private cars is relatively stable. The traffic efficiency is increasing by about $18 \%$ every 2 years, and the carbon emissions are stable although the total traffic volume has been growing. As a result, the value of objective function $Z_{n}$ is also increasing, which indicates the least carbon emissions and the most amount of traffic flow.

\section{Conclusions}

Since the concept of "low-carbon traffic" has been put forward so far, major cities are all taking measures to achieve the goal of low carbon. This paper proposes the low-carbon optimization model of traffic and analyses the case of Zhengzhou, which is the first batch of "transit city" pilot. The result has a good verification for low-carbon traffic.

This paper still has many deficiencies. Constraints are not comprehensive enough, and future data may have great changes. Urban traffic system includes multiple modes of traffic, while this paper only selects the four major representative modes. Data need to be further refined when making decision and variables should be put into the model.

In the long term, researchers can focus on the matter of time and expand dynamic model. Green traffic(walk, bicycles, electric bicycles) can also be discussed further.

\section{Acknowledgements}

This research is supported by the Fundamental Research Funds for the Central Universities (2014JBM070).

\section{References}

[1] Hickman R, Ashiru O, Banister D. Transport and climate change: Simulating the options for carbon reduction in London[J]. Transport Policy, 2010, 17(2): 110-125.

[2] Chadha S S, Chadha V. Linear fractional programming and duality[J]. Central European Journal of Operations Research, 2007, 15(2): 119-125.

[3] Wang, Y.F., Calculation of carbon emissions about motor vehicles in Chengdu[D]. Southwest JiaoTong University, 2011.

[4] Wang, H.K., Zhang, R.R., Bi J. Accounting of Chinese urban carbon emissions_—Wuxi[J]. China Environmental Science, 2011, 31(6): 1029-1038.

[5] Jia, P.P, Tao, C., Energy consumption calculation of integrated urban traffic[D]. Chang'an University, 2012.

[6] Zhang, Q., Tao, X.M., Yang, P., Research on carbon emissions from metropolis urban passenger transport and countermeasures[J]. China population, resouces and environment, 2012, 22(1): $35-42$. 
[7] Cheng, L., Research on Urban Passenger Traffic Distribution Optimization Based on Low Carbon Emission[D]. Huazhong University of Science and Technology, 2012.

[8] Zhang, H.Z., Gao, Z.Y., Zhang, B., Model and algorithm of transportation network design for emission reduction[J]. China Civil Engineering Journal, 2007, 39(11): 114-119.

[9]Zhao, M., Hu, J., Dai, Q., The Accounting of $\mathrm{CO}_{2}$ Emissions Based on the Energy Balances[J]. Ecological Economy, 2012 (011): 30-32.

[10] Ning, X.J., Research on traffic carbon emissions of urban residents in Zhengzhou city. Henan University, 2013. 